\title{
PERSPECTIVAS DA EDUCAÇÃO PERMANENTE EM SAÚDE
}

Fernanda de Oliveira SARRETA ${ }^{1}$

Iris Fenner BERTANI ${ }^{2}$

\begin{abstract}
RESUMO: A Educação Permanente em Saúde (EPS) é uma estratégia político-pedagógica reconhecida mundialmente para consolidar os sistemas públicos de saúde, uma vez que a formação dos profissionais está voltada para as demandas do mercado capitalista e não atende as necessidades de saúde da população. A difusão da EPS pela Organização Pan-Americana de Saúde e Organização Mundial de Saúde tem como base o processo de trabalho e a valorização das vivências e das experiências dos sujeitos sociais. No Brasil a educação foi considerada um elemento funcional do Sistema Único de Saúde (SUS) e a EPS ganhou regulamento de política pública em 2004. A articulação intersetorial entre o Ministério da Saúde e o Ministério da Educação, no sentido de discutir e orientar mudanças na graduação das profissões da área da saúde, para implementação de diretrizes curriculares nacionais e renovação dos projetos pedagógicos dos cursos, apresenta a intenção de adequar a formação profissional e o desenvolvimento de recursos humanos em saúde, para que estejam vinculados aos princípios da integralidade da atenção e respondam às necessidades dos serviços. Ao seguir os princípios e as diretrizes organizacionais do SUS, a EPS visa fortalecer o modelo de atenção, a promoção e prevenção em saúde, para que a atenção integral seja a referência do trabalho visando a autonomia dos sujeitos na produção da saúde. Para tanto, busca a formação de um profissional crítico, criativo, com capacidade para “aprender a aprender”, e que considere a realidade social para oferecer atendimento ético, humanizado e de qualidade.
\end{abstract}

PALAVRAS-CHAVE: Educação permanente em saúde. Política de saúde. Sistema único de saúde.

\section{Introdução}

A partir da proposta apresentada pelo IV EIDE - Encontro Iberoamericano de Educação, o artigo convida para um debate acerca da importância da educação na área da saúde e das perspectivas apresentadas pela Política de Educação Permanente em Saúde (EPS) para a formação dos trabalhadores do Sistema Único de Saúde (SUS). Este material é resultante de uma pesquisa qualitativa, nível doutorado, realizada no Programa de PósGraduação em Serviço Social da UNESP, Campus de Franca/SP, onde buscou-se analisar e estudar experiências que potencializam a educação permanente como estratégia de aprendizagem na saúde.

\footnotetext{
$1 \quad$ UNESP - Universidade Estadual Paulista. Faculdade de História, Direito e Serviço Social - Programa de Pós-Graduação em Serviço Social. Franca - SP - Brasil. 14.409-160 - fersarreta2009@yahoo.com.br

UNESP - Universidade Estadual Paulista. Faculdade de História, Direito e Serviço Social - Programa de Pós-Graduação em Serviço Social. 14.409-160 - irisbertani1311@yahoo.com.br
} 
Atualmente, existe uma movimentação intersetorial entre o Ministério da Saúde e o Ministério da Educação, no sentido de discutir e orientar mudanças na graduação das profissões da área da saúde, para implementação de diretrizes curriculares nacionais e renovação dos projetos pedagógicos dos cursos. Essa parceria apresenta a intenção de adequar a formação profissional e o desenvolvimento de recursos humanos em saúde, para que estejam vinculados aos princípios da integralidade da atenção e respondam às necessidades dos serviços de saúde.

A discussão crítica da articulação saúde/educação, enquanto políticas balizadoras da formação de profissionais de saúde têm sido acompanhadas em conjunto com as Unidades de Ensino do país, Associações, grupos de profissionais, como o Fórum Nacional das Associações Brasileiras de Ensino das Profissões da Saúde (FNEPAS), um processo profundamente analisado por distintos atores participantes (MOTA et al., 2006).

A Política de EPS materializa as reivindicações coletivas da saúde pública brasileira. Mostra-se avançada e consoante com as diretrizes e princípios do SUS, e com as orientações da Organização Pan-Americana de Saúde e Organização Mundial de Saúde (OMS, 2007) ao adotar a EPS como estratégia de aprendizagem, tendo como base os processos de trabalho, valorizando as vivências e as experiências dos sujeitos sociais.

\section{A formação para a saúde}

De acordo com a Política de Educação Permanente em Saúde (BRASIL, 2004), a integralidade do atendimento é a referência central para orientar as ações de saúde voltadas, ao mesmo tempo, para o indivíduo, a família e a comunidade, em grau de complexidade crescente e nos aspectos preventivo, curativo e de promoção. Sua implantação precisa, portanto, estar articulada aos princípios da intersetorialidade e com equipes multiprofissionais para romper a formação fragmentada e reafirmar os princípios do SUS. A EPS destina-se à transformação do modelo de atenção, fortalecendo a promoção e a prevenção em saúde, para que a atenção integral seja a referência do trabalho visando a autonomia dos sujeitos na produção da saúde. Para tanto, conforme analisam Bertani, Sarreta e Lourenço (2008), busca a formação de um profissional crítico, criativo, com capacidade para “aprender a aprender”, e que considere a realidade social para oferecer atendimento ético, humanizado e de qualidade, contribuindo para a qualidade do atendimento.

Como eixos norteadores para esses processos de mudança a Política apresenta a articulação do quadrilátero do SUS: ensino - serviço - gestão - controle social. Ceccim e 
Feuerwerker (2004, p.47) esclarecem que a importância do “quadrilátero da formação” tem-se pela relevância da integração podendo ser uma experiência inovadora com a finalidade de aproximar a formação dos trabalhadores das reais necessidades de saúde. Para os autores compete tanto ao SUS como às instituições formadoras “[...] coletar, sistematizar, analisar e interpretar permanentemente informações da realidade, problematizar o trabalho e as organizações de saúde e de ensino, e construir significados e práticas com orientação social.” (CECCIM; FEUERWERKER, 2004, p.46).

Dessa perspectiva, a formação na área da saúde deve considerar não apenas as exigências dos postos de trabalho do setor saúde, que seguem as orientações do mercado e que exigem cada vez mais um trabalhador treinado e preparado para a produção e reprodução do capital. O trabalho na saúde, como alertam Ceccim e Feuerwerker (2004, p.49), “[...] é um trabalho de escuta, em que a interação entre profissional de saúde e usuário é determinante da qualidade da resposta assistencial”. A área da saúde requer educação permanente, uma vez que “[...] a incorporação de novidade tecnológica é premente e constante, e novos processos decisórios repercutem na concretização da responsabilidade tecnocientífica, social e ética do cuidado, do tratamento ou do acompanhamento em saúde.” (CECCIM; FEUERWERKER, 2004, p.49).

Nesta perspectiva, a lógica da Política de EPS é descentralizadora, ascendente e transdisciplinar, visando o desenvolvimento da autonomia das pessoas, a descentralização da gestão e participação, e a mudança do modelo de assistencial centrado na doença e nos procedimentos fragmentados que valorizam as especialidades. Propõe a ruptura do sistema verticalizado na saúde, em que alguns detêm o saber e o poder, para trabalhar com um conjunto articulado de serviços básicos, de especialidades e hospitalares, em que todas as ações de saúde devem ser prestadas reconhecendo as necessidades das pessoas envolvidas (BRASIL, 2004). Um processo de educação permanente é profundamente democrático, como assinala a OPAS (ROVERE, 1994), pois implica em começar a aprender a perguntar, e não a estabelecer respostas prontas. É um processo que só pode se sustentar sobre a base de um trabalhador que é sujeito do seu processo de trabalho, ainda que isto contradiz a cultura dominante dos serviços de saúde. Por isso a EPS demanda organizações mais democráticas e a construção de espaços que possibilitem a reflexão.

Ceccim (2005, p.161) esclarece que “como vertente pedagógica” a educação permanente ganhou estatuto de política pública na área da saúde, pela difusão da OPAS para alcançar o desenvolvimento dos sistemas de saúde na região: “[...] os serviços são organizações complexas em que somente a aprendizagem significativa será capaz de adesão 
dos trabalhadores nos processos de mudanças no cotidiano.” A saúde tem, assim, o desafio de incorporar o processo educativo ao cotidiano de trabalho. Dessa perspectiva, a educação permanente estimula a reflexão no mundo do trabalho e pode contribuir para melhorar a qualidade da assistência, incorporando nas ações de saúde os princípios e valores do SUS - da integralidade da atenção, da humanização do cuidado e do reconhecimento da autonomia e dos direitos dos usuários dos serviços de saúde. A construção desse aprendizado é necessária para um novo modo de fazer saúde.

A evidência, portanto, do uso de novas tecnologias na formação em saúde assinalam que as instituições de educação precisam melhorar o seu desempenho e podem oferecer contribuições sobre a intensificação de habilidades, capacidades, para adequar o perfil profissional às necessidades da área da saúde. A definição de EPS pela OMS (ROVERE, 1994), compreende a educação no trabalho, pelo trabalho e para o trabalho, nos diferentes serviços, cuja finalidade é melhorar a saúde da população. Está, portanto, diretamente relacionada à qualidade do atendimento da atenção, que quando não é satisfatória transformase num grande problema social. Isto torna evidente que, sendo os serviços de saúde, serviços de pessoas para pessoas, o principal fator de qualidade da atenção está constituído pela disponibilidade, atitude, conhecimento e desempenho da saúde.

Nesse sentido, a OPAS e OMS compreendem que a EPS é da mesma maneira: ferramenta para a investigação e a (auto) análise do trabalho, instrumento de problematização, mecanismo para elaborar conflitos, proposta de busca e incorporação crítica de novas tecnologias e de novos procedimentos, ou seja, novas formas de fazer as coisas, podendo constituir-se em uma das principais estratégias para melhorar a qualidade dos serviços de saúde. Isto não significa que as diversas atividades de formação e capacitação no setor saúde correspondem ao que se caracteriza como educação permanente, uma vez que, “[...] os processos educativos neste campo podem ser considerados como intervenções capazes de mobilizar, circular, produzir e transferir conhecimento, tecnologia, valores e sentimentos.” (ROVERE, 1994, p.25).

\section{A educação permanente em saúde}

Desde a institucionalização do Sistema Único de Saúde (SUS), a partir da Constituição Federal de 1988, a questão da formação profissional tem sido realçada como fundamental, e é a que vem sofrendo o maior processo de desregulamentação dentro da política do Estado no país. Os ideais de cidadania e dignidade da pessoa humana, como 
direitos fundamentais, foram inscritos no texto constitucional elevando à condição de relevância pública as ações e os serviços de saúde, na medida em que ordena a saúde um direito fundamental do cidadão.

Entretanto, as transformações que vêm ocorrendo no mundo - no âmbito econômico, tecnológico, cultural, político, estão provocando mudanças nos paradigmas de educação e de formação profissional, no sentido de, cada vez mais, responder às exigências do mundo do trabalho. Os principais problemas podem ser resumidos como: a formação inadequada, com currículos que não se baseiam nas necessidades de saúde; pouco acesso dos trabalhadores da saúde a recursos de informações e conhecimento; condições inadequadas e inseguras no local de trabalho; políticas e práticas insuficientes para o desenvolvimento de recursos humanos, como apresenta a OMS (2007). A precarização do trabalho e o aprofundamento do modelo curativista/hospitalocêntrico têm sido apontados pela necessidade da formação dos trabalhadores, há várias décadas nos espaços das conferências de saúde.

Assim, a compreensão predominante do processo de educação, no contexto brasileiro, expressa as idéias e as práticas do sistema capitalista, que não representam uma agenda estratégica capaz de refletir as demandas sociais e as representações da complexa estrutura da sociedade. Tornam-se incapazes de ir além dos problemas aparentes e particulares e transcenderem para o coletivo, no reconhecimento da desigual concentração de renda, do processo de trabalho, de oportunidades educacionais, ao acesso à saúde, à água potável e à moradia de qualidade, entre outras questões. Portanto, a ênfase da educação na sociedade atual é a do mercado, o que torna então necessário esclarecer que educação permanente em saúde, no entendimento do SUS, refere-se ao processo de ensino-aprendizagem, é “[...] a aprendizagem no trabalho, onde o aprender e o ensinar são incorporados ao quotidiano das organizações e do trabalho.” (BRASIL, 2005, p.12).

Considerada um suporte na implementação do SUS, de tal modo que efetive o conceito ampliado de saúde, a educação permanente em saúde difere das propostas de transferência de conhecimentos, que aponta as necessidades cada vez mais exigentes de um perfil de trabalhador polivalente, qualificado ou ainda, bem treinado. Assim, a abrangência do processo de educação transportado para as questões de saúde pode desencadear ações educativas sustentadas nos paradigmas referenciais da promoção humana. Pode, então, ser uma estratégia para transcender o pensamento tradicional (agente-corpo-hospedeiro), ainda vigente na prática dos serviços de saúde, para promover a reflexão das condições materiais de vida e seus laços fecundos na saúde. 
A ação de EPS não trata de capacitação ou treinamento, mas da construção de conhecimentos numa vinculação horizontal, intersetorial e interdisciplinar. Prioriza a relação ensino-aprendizagem movida pelo debate crítico e discussões das exigências presentes no cotidiano dos serviços de saúde, o que significa que o ponto de partida são os problemas ou a problematização da realidade concreta. É, nessa abrangência, uma estratégia que parte do pressuposto da aprendizagem significativa, a aprendizagem que produz sentido para o sujeito, faz a interlocução com os problemas enfrentados na realidade, e leva em consideração os conhecimentos e as experiências que as pessoas possuem (BERTUSSI, 2004). A aprendizagem é incorporada no cotidiano de trabalho, “[...] para efetuar as relações orgânicas entre ensino e as ações e serviço, e entre docência e atenção à saúde, sendo ampliado na Reforma Sanitária brasileira, para as relações entre formação e gestão setorial, desenvolvimento institucional e controle social em saúde.” (BRASIL, 2004, p.6).

Para que a aprendizagem se torne significativa, a construção do conhecimento passa pela problematização. "Problematizar significa refletir sobre determinadas situações, questionando fatos, fenômenos, idéias, compreendendo os processos e propondo soluções” (BRASIL, 2005, p.8). Ao refletir sobre a situação concreta de trabalho, as propostas de soluções passam a ser mais reais, viáveis e, sobretudo, descentralizadas e compartilhadas. Os processos de formação dos trabalhadores da saúde devem, portanto, se estruturar a partir da problematização das práticas cotidianas e dos problemas que impedem a atenção integral e a qualidade do atendimento. Esse processo permite a reflexão do mundo do trabalho e dos problemas vivenciados na área, sendo que estas dificuldades são objeto da Política de EPS.

A respeito da metodologia da problematização, Berbel (1998) cita o Método do Arco, utilizando-se de um desenho da realidade numa escala de cinco etapas, quais sejam: observação da realidade social; pontos-chave; teorização; hipóteses de solução e aplicação à realidade (prática). Esta é uma alternativa metodológica onde os próprios sujeitos procuram compreender a relação dos aspectos, nem sempre diretos, mas que interferem na existência daquele problema identificado. "Tal complexidade sugere um estudo mais atento, criterioso, crítico e abrangente do problema, em busca de sua solução.” (BERBEL, 1998, p.144). O exercício cognitivo acerca dos problemas e suas possíveis soluções tem o sentido especial de levar a exercitar “[...] a cadeia dialética de ação - reflexão - ação, ou dito de outra maneira, a relação prática - teoria - prática, tendo como ponto de partida e de chegada do processo de ensino e aprendizagem, a realidade social.” (BERBEL, 1998, p.144).

Evidencia-se, aqui, que a implantação da Política de EPS privilegiou a utilização da problematização, enquanto metodologia eminentemente participativa, considerada inclusiva 
ao trabalho de campo, implicando no envolvimento pró-ativo de todos os atores sociais (CYRINO; TORALLES-PEREIRA, 2004). Essa estratégia ao ser construída a partir da realidade percebida no dia-a-dia dos trabalhadores da saúde tornaria possível o respeito a seus anseios, necessidades e carências, debatidos no coletivo. A ênfase nessa metodologia salienta a contribuição das diferentes práticas, possibilita aos sujeitos a interagirem com o meio, com vistas à sua preparação para a tomada de consciência de seu mundo. Ela tem a finalidade de propiciar a atuação intencional no real e "transformá-lo, sempre para melhor, para um mundo e uma sociedade que permitam uma vida mais digna para o próprio homem”, como reflete Berbel (1998, p.145).

Importa lembrar que Freire (1978) já havia problematizado a questão da educação, ao situar o caráter acrítico, autoritário e seletivo da educação. E, reforçou o ponto de vista metodológico da educação libertadora e humanista, a qual deve partir de um processo educativo baseado no diálogo e na participação. Para o autor, o importante nesse processo é que os homens se reconheçam como sujeitos de seu pensar, buscando dialogicamente o seu pensar e a sua visão do mundo. Freire (1978) questiona também se é possível praticar uma educação dialógica, uma vez que a educação problematizadora é dialogar sobre a negação do próprio diálogo, onde tanto o educador como o educando tornam-se sujeitos do processo.

A problematização, para Freire (1978, p.126), é a “[...] identificação daquelas situações-limites, que estão no cerne das contradições da sociedade, e que muitas vezes se afiguram aos homens como barreiras insuperáveis.” É, em si, a atitude de compreender e transformar estas "situações-limites” em um novo conteúdo da educação, para superá-las. O objetivo da educação problematizadora, como orienta Freire (1978, p.126), é dar rapidez à ultrapassagem da “consciência real” para a “consciência possível”, como de expressão e de criatividade, procurando o melhor caminho que possibilite exercer o seu papel de sujeito do conhecimento no processo de sua aprendizagem.

Expressando de outra maneira, na saúde a educação problematizadora tem como objetivo contribuir na relação entre os sujeitos, de uma postura dialógica, de intercâmbio de informações e de experiências, para o reconhecimento da existência dos saberes distintos, dando um sentido de totalidade e integralidade ao trabalho. As contribuições da prática são, portanto, problematizadas e configuram-se uma forma de estimular o debate e a teorização, numa relação de constante diálogo educador-educando. Essa exploração temática deve acontecer num espaço de negação e reafirmação, extrapolando os conteúdos formais já cristalizados no modo de ensino tradicional, transcendendo para a reflexão, construindo o patamar da realidade pensada e levando às proposições de novas intervenções. 
Não se trata de um exercício de estímulo de criatividade para a resolução de problemas imediatos, mas da provocação de questionamentos reflexivos sobre as ações e atitudes profissionais cotidianas. Educador e educando vêem-se como sujeitos políticos, históricos e culturais, diante do processo de transformação da realidade que se mostra insatisfatória no atendimento da área da saúde.

\section{Considerações}

A importância do reconhecimento da EPS na atualidade é assinalada para a mudança de paradigma, de (re)organização dos programas de saúde, dos serviços e das práticas desenvolvidas. A proposta tem fundamentação no processo de implementação do SUS enquanto direito social e política pública, construindo espaços democráticos na busca de respostas e soluções para melhorar a qualidade de saúde.

O pressuposto básico é a desconstrução das ações dicotomizadas nas práticas individuais para avançar na edificação permanente do processo de “aprender a aprender” ou “aprender a construir saúde”, que de antemão exige o exercício do trabalho em equipe voltado ao processo educativo que valorize o conhecimento tido como "não-científico" e aquele reconhecido como científico; e que seja estruturado sob o conceito ampliado de saúde, no qual as várias disciplinas alternam papéis na construção da atenção integral a saúde e sua promoção. É neste sentido, que as práticas de educação saem das agendas acadêmicas para se integrarem às práticas dos serviços públicos de saúde. O processo de “aprender a construir saúde” implica na formação permanente dos trabalhadores da saúde, na perspectiva da aprendizagem significativa, como possibilidade para construção de sujeitos ativos na reflexão crítica sobre os processos de trabalho no SUS (BERTANI; SARRETA; LOURENÇO, 2008).

Desta perspectiva, o desenvolvimento da consciência crítica processa-se por intermédio de procedimentos pedagógicos que toma como referência de aprendizado a experiência de vida do sujeito para transformação da realidade, um gesto de libertação de uma situação de ignorância/opressão, como ensina Freire (2006). A educação que intenciona o conhecimento crítico tem que levar em conta as experiências vividas pelos sujeitos, senão não há aprendizado e nem reflexão crítica, já que o ato de conhecimento nasce da relação entre o conteúdo e o cotidiano, uma vez que estimula a pensar na própria vida.

Estas questões demonstram a importância de ampliar a formação e qualificação dos trabalhadores da saúde, na dimensão técnica, ética e política, e nas inter-relações pessoais, para que participem como sujeitos integrais no mundo do trabalho. A área da saúde tem, 
assim, o desafio de desenvolver um processo que permita identificar e promover os saberes e os conhecimentos dos trabalhadores, para melhorar a qualidade da assistência, e do próprio atendimento, incorporando em suas ações os princípios e valores que orientam o SUS (SARRETA; ETO, 2007). É um caminho que pode oferecer pressupostos para orientar a formação profissional na saúde, tanto na perspectiva do mundo do trabalho quanto na perspectiva educacional.

\section{PERMANENT EDUCATION PERSPECTIVE ON HEALTH}

ABSTRACT: Permanent health education (EPS) is an educational policy strategy recognised worldwide to consolidate public health systems, since the training of professionals is focused on the capitalist market demands and does not meet the needs of population health. The EPS broadcast by the Pan American Health Organization and by the World Health Organization is based on the work process and on the evaluation of experiences of the social subjects. In Brazil the education was considered a functional element to the Unique Health System (SUS) and the EPS won public policy regulation in 2004. The intersectoral articulation between the Ministry of Health and the Ministry of Education, to discuss and targeting changes in the graduation of the healthcare professions, for implementing national curriculum guidelines and renewal of the teaching projectes of the courses, presents the intention to align the appropriete training and human resources development in health, in order that they are bound to the principles of integrality of attention and respond to the needs of the services. By following the organizational principles and guidelines, the EPS of the SUS aims to strengthen the model of attention on health promotion and prevention, in order that the whole attention of the work could be the reference to the autonomy of the citizen in the production of health. So, it strives to do the training of a creative, critical professional, with the competence of "learning to learn", and that considers the social reality in order to provide ethical, participatory and qualified care.

KEYWORDS: Education on health. Health policy. Unique health system.

\section{REFERÊNCIAS}

BERBEL, N. A. N. A problematização baseada em problemas: são diferentes termos ou diferentes caminhos? Interface: Comunicação, Saúde e Educação, Botucatu, n.2, p.139154, fev. 1998.

BERTANI, I. F.; SARRETA, F. de O.; LOURENÇO, E. Â. de S. Aprendendo a construir saúde: desafios na implantação da política de educação permanente em saúde. Franca: Ed. UNESP, 2008.

BERTUSSI, D. Caminhos para a educação permanente. Brasília: Ministério da Saúde, 2004. 
BRASIL. Secretaria de Gestão do Trabalho e da Educação na Saúde. Departamento de Gestão da Educação na Saúde. Curso de formação de facilitadores de educação permanente em saúde: unidade de aprendizagem Trabalho e Relações na Produção do Cuidado. Brasília: SGTES, 2005.

. Ministério da Saúde. Portaria no 198/GM - MS, de 13 de fevereiro de 2004. Institui a Política Nacional de Educação Permanente em Saúde como estratégia do Sistema Único de Saúde para a formação e o desenvolvimento de trabalhadores para o setor e dá outras providências. Brasília: Ministério da Saúde, 2004.

Constituição (1988). Constituição da República Federativa do Brasil. 18. ed. Brasília: Senado, 1988.

CECCIM, R. B. Educação permanente em saúde: desafio ambicioso e necessário. Interface: Comunicação, Saúde, Educação, Botucatu, v.9, n.16, p.61-177, 2005.

CECCIM, R. B.; FEUERWERKER, L. C. M. O quadrilátero da formação para a área da saúde: ensino, gestão, atenção e controle social. Physis: Revista de Saúde Coletiva, Rio de Janeiro, v.14, n.1, p.41-65, 2004.

CYRINO, E. G.; TORALLES-PEREIRA, M. L. Trabalhando com estratégias de ensinoaprendizagem por descoberta na área da saúde: a problematização e a aprendizagem baseada em problemas. Cadernos de Saúde Pública, Rio de Janeiro, v.20, n.3, p.780-788, maio/jun. 2004.

FREIRE, P. Pedagogia do oprimido. Rio de Janeiro: Paz e Terra, 1978.

Pedagogia da autonomia: saberes necessários à prática educativa. São Paulo: Paz e Terra, 2006.

MOTA, A. E. et al. (Org.). Serviço social e saúde: formação e trabalho profissional. São Paulo: OPAS: OMS: Ministério da Saúde, 2006.

ORGANIZAÇÃO MUNDIAL DA SAÚDE [OMS]. Relatório mundial de saúde, 2006: trabalhando juntos pela saúde. Brasília: Ministério da Saúde: OMS, 2007. Disponível em: <http://www.opas.org.br/mostrantp.cfm?codigodest=586>. Acesso em: 4 mar. 2007.

ROVERE, M. R. Gestión estratégica de la educación permanente en salud. In: HADDAD, J.; ROSCHKE, M. A. C.; DAVINI, M. C. Educación permanente de personal de salud. 1994. Disponível em: <http://www.opas.org.br/mostrantp.cfm?codigodest=586>. Acesso em: 12 mar. 2007.

SARRETA, F. de; ETO, F. Educação em saúde: construindo experiências na formação e na prática profissional. In: BERTANI, I. F.; REZENDE, R. M. (Org.). Conversas interessantes sobre saúde: programa de extensão QUAVISSS. São Paulo: Ed. UNESP, 2007. 